O eixo e a roda, Belo Horizonte, v.25, n.2, p. 27-46, 2016

\title{
$O$ conto rural entre dois séculos: notas sobre algumas de suas transformações ${ }^{1}$
}

\section{The rural short story between two centuries: notes about some of its transformations}

\author{
Fernando Cerisara Gil \\ Universidade Federal do Paraná (UFPR), Curitiba / Brasil \\ fcgil61@gmail.com
}

Resumo: $\mathrm{O}$ artigo analisa as transformações ocorridas na contística da passagem das últimas décadas do século XIX para as primeiras décadas do século XX e sua relação com a matéria rural. O ponto de vista formulado sugere que é nesse último período que se empreende o primeiro esforço expressivo de fazer da matéria rural elemento estruturalmente constitutivo da nossa ficção.

Palavras-chave: conto rural; matéria rural; literatura e sociedade.

Abstract: This article analyzes the changes occurred in the short story from the last decades of the 19th century to the first decades of the 20th century and its relation with the rural matter. The point of view presented here argues that it is during the latter period that a significant effort to make the rural element structurally constitutive of our rural fiction has taken place. Keywords: rural short story; rural matter; literature and society.

Recebido em 30 de abril de 2016.

Aprovado em 20 de maio de 2016.

\footnotetext{
${ }^{1}$ Este ensaio constitui resultado parcial da pesquisa em curso "A duplicidade da ficção rural brasileira: o estatuto do narrador, a representação do 'outro' e o 'estilo' da prosa rural'", financiada pelo CNPq.
} 
As formulações que se seguem talvez sejam menos do que uma hipótese de trabalho, mas mais do que intuições. Menos do que uma hipótese porque as suas premissas, noções conceituais e demonstrações analíticas se encontram em fase exploratória, por assim dizer, não se caracterizando, ainda, como um sistema explicativo mais ou menos coerente a dar conta de um objeto e seus problemas. Mais do que intuições porque questões próximas ou correlatas às que se pretende tratar aqui já foram foco de nossa atenção em relação ao gênero romanesco. ${ }^{2} \mathrm{O}$ objetivo, neste momento, é fazer algumas anotações sobre determinados aspectos do conto rural no começo do século XX. A discussão proposta parte de uma ideia-força sobre a qual gostaríamos de nos deter a fim de examinar algumas de suas implicações.

A ideia-força que move a nossa abordagem e discussão se refere à noção de que foi no fim do século XIX e no começo do século XX que nossos escritores e homens de letras em geral perceberam ou começaram a formular, na sua maneira de compreender, sentir e idear o país, a perspectiva segundo a qual este se caracterizaria por uma diferença profunda e radical entre campo e cidade, entre litoral e "sertão", entre vida rural e urbana, entre homens da cidade e homens dos "grotões". Isso tanto do ponto de vista da consciência histórico-social quanto do ponto de vista da consciência literária. ${ }^{3}$

Não que a consciência dessa diferença, bem entendido, não estivesse presente em momentos anteriores. Para dar exemplo de sua manifestação, basta lembrar o começo da narrativa O índio Afonso (1873), de Bernardo Guimarães, em nosso romantismo:

Bem quisera eu fazer-vos passear em companhia de meus personagens por uma enfiada de magníficos salões dourados, pisando em ricos e mimosos tapetes, no meio da mais polida e perfumada sociedade do mundo, ou embaladas em macios coupés a trote largo, através de ruas

\footnotetext{
${ }^{2}$ Desenvolvemos algumas hipóteses de trabalho no estudo $A$ matéria rural e a formação do romance brasileiro: o romance rural no século XIX (a sair).

${ }^{3}$ Não nos interessa, por agora, as possíveis explicações de uma teoria social para os descompassos histórico-temporais e suas formas de reprodução no interior de nossa formação social. Objetivamos identificar como esta dualidade/dicotomia passou a ser uma forma de sentir, avaliar e compreender o país e tudo que o envolve num determinado momento histórico.
} 
e praças de uma esplêndida cidade, ou por entre alamedas de um suntuoso jardim, aspirando os aromas dos lilases, asfodélias, e cinamomos, ou mesmo em algum vagão de primeira classe, varando distâncias enormes com rapidez vertiginosa, visitando cidades monumentais, percorrendo países de lindas tradições romanescas, juncados de prodígios de arte antiga e moderna, ou...

Bem quisera eu muita cousa, mas não me é possível. $[\ldots]$

E isso não me é possível, já o disse. A minha musa é essencialmente sertaneja; sertaneja de nascimento, sertaneja por hábito, sertaneja por inclinação.

E pois não tenho remédio senão levar-vos comigo pelas broncas e selvosas ribanceiras do caudaloso Parnaíba, através de espessas matas, ouvindo apenas o zunido da ventania pela cabeleira desgrenhada das bravias matas, e o ronco das cachoeiras pela quebrada das penedias, cuja enfadonha monotonia não deixa contudo de ser de quando em quando disfarçada pelos urros formidáveis de alguma sussurana, ou pelo bramido surdo que solta o sucuri no fundo das águas, quando ouve nos céus o rolar do trovão. E, o que é pior ainda, não tenho remédio senão levarvos a conviver por algumas horas com uma súcia de caboclos quase selvagens, sem tintura de civilização, descalços e de chapéu de couro, tendo por único ornato uma comprida faca na cintura e um enorme cigarro na boca (GUIMARÃES, [s.d.], p. 363-364).

Em seu tom deliciosamente galhofeiro, o narrador assinala a posição incontornável de sua matéria na qual a "musa [que] é essencialmente sertaneja; sertaneja de nascimento, sertaneja por hábito, sertaneja por inclinação", se contrapõe à finesse de suas virtuais leitoras citadinas. Está situada, desde aí, a dicotomia para qual estamos chamando atenção, expressa na tensão, enunciada pelo narrador, entre matéria rural e a posição social e histórica da recepção, como se diria hoje em dia. Se já se encontra demarcada certa compreensão da diferença entre mundo rural e mundo urbano, entre "os grotões" do país e o espaço citadino, isso não significa, no entanto, que esta diferença seja reconhecida sistematicamente como diferença literária e social antes do fim do século XIX e início do século XX. Com efeito, ao longo do romantismo e até 
mais ou menos pelos idos dos anos 1880, a presença da matéria rural se coloca como um forte e sistemático esforço, por parte dos nossos escritores, de incorporá-la ao repertório simbólico e afetivo do país, que se concebia como nação jovem. Repertoriar os elementos que poderiam constituir aspectos variados da paisagem física, material e humana do país e dar-lhes estatuto literário, ou seja, atribuir-lhes algum grau de dignidade e de reconhecimento para se tornar objeto respeitável de fruição simbólica e ideológica, parece ser o objetivo precípuo, nessa quadra. Não para menos, a linguagem que poderia enunciar este mundo até certo ponto excêntrico ao sistema sociocultural dominante seria a "palavra culta". Nesse momento, somente a linguagem culta e citadina poderia dar reputabilidade ao mundo rural configurado literariamente, pois este somente poderia ser reconhecido como extensão do mundo dos homens letrados, como "coisa" a lhe pertencer e a que esses homens dariam voz. Não se reconhece ou desbaste-se qualquer traço de particularidade mais evidente e relevante.

A mudança desse quadro ao longo do tempo sugere ter decorrido de fatores literários, culturais, históricos e sociais variados, complexos e muitas vezes relacionados entre si, cuja descrição e análise não temos condições de fazer neste momento. Para os limites deste ensaio, é importante, no entanto, ao menos indicar elementos envolvidos nesta mudança e a sua relação com o tema que aqui se tem em vista. Um deles diz respeito à percepção da modernização imprimida ao país ao longo da segunda metade do século XIX, da qual uma das maiores consequências parece ter sido a demarcação e diferenciação dos espaços sociais na formação social brasileira. Ainda que no período em exame, a década final do XIX até os dois primeiros decênios do século XX, como se sabe, a vida social e econômica brasileira fosse predominantemente agrária, vivida no campo e nas pequenas cidades que são ainda quase que extensão daquele, ${ }^{4}$ isso não foi obstáculo para que se formasse uma consciência social, por parte de nossas elites, homens de letras e intelectuais, que passou a estabelecer uma fronteira nítida entre campo e cidade, entre os modos de vida urbano e rural. Da capital do país já agora república, o

\footnotetext{
${ }^{4}$ Segundo Emília Viotti da Costa, no ensaio "A urbanização no Brasil no século XIX", comparando o total da população do país com o da que vivia nas capitais em 1872, 1880 e 1900, temos o seguinte quadro evolutivo: 1872 : $10.112 .061-1.022 .655 ; 1890$ : 14.330.915 - 1.133.087; 1900: 17.318.556-2.032.284 (COSTA, 1999, p. 265).
} 
Rio de Janeiro, emanava para outros centros urbanos a aspiração de um mundo cosmopolita, citadino e refinado. Ela simbolizava e incorporava em si o desejo de atualização modernizadora do estilo de vida e da cultura nacionais. Vale destacar que esta visão por vezes eufórica não emerge sem a sua contraface, que pode ser traduzida pelo sentimento expresso pelos escritores de que somos dotados de uma cultura defeituosa, falha, "que não possui a continuidade perfeita, a coesão, a unidade das grandes literaturas" (VERÍSSIMO, 2014, p. 499), por exemplo. Trata-se de perceber em âmbitos diferentes, mas presentes no conjunto do tecido social, "algumas das influências contrárias ao desenvolvimento orgânico do país" (NABUCO, 2000, p. 168), o qual não conseguira, até aquele momento, chegar a "uma existência mental mais definida" (ROMERO, 2014, p. 439). ${ }^{5}$ Conforme a perspectiva do autor e o que estivesse em debate, os entraves de nossa incompletude poderiam ser situados e ter como razão a escravidão e a sua herança, quem sabe a cultural rarefeita e malformada do país, ou ainda a sua formação étnica miscigenada que determinava um "desvio" do padrão branco europeu, entre outras.

Sílvio Romero, no mesmo ensaio citado acima, já se atentava para esta consciência e sentimentos ambíguos das camadas dominantes e dos homens de letras ao observar que não havia meio termo: "Ou somos um prodígio de grandeza; ou o mais aviltado de todos os povos" (ROMERO, 2014, p. 440). Tudo indica que é nesse contexto que o espaço rural parece surgir como distinto e ao mesmo tempo dicotômico em face do espaço urbano. ${ }^{6}$ A "produção social do espaço de forma dicotômica"

\footnotetext{
${ }^{5}$ Para enfatizar a mudança de perspectiva para a qual estamos chamando a atenção, observe-se que os ensaios referidos foram publicados no seguinte leque temporal: " $\mathrm{O}$ nacionalismo literário", de Sílvio Romero, em 1873, O abolicionismo, de Joaquim Nabuco, em 1884, e "O que falta à nossa literatura", de José Veríssimo, em 1899.

${ }^{6}$ As relações entre cidade e campo, espaço rural e urbano são, como se sabe, complexas e instáveis, porque histórica e socialmente mutáveis ao longo do tempo. Para os nossos objetivos, o seu estudo somente se torna produtivo se tentarmos recuperar a historicidade de seu processo. Tal historicidade, bem como o seu estudo, pode ter clivagens diferentes considerando o que está em foco e seu respectivo âmbito de análise. Podemos dizer, para explicitar a questão, que a sociologia brasileira formulou um aparato teórico e metodológico para o exame dessas relações que significou um grau de acumulação, de adensamento e de especialização, que está relacionado ao nível de importância do problema para a área. (Não nos interessa aqui destacar as razões dessa importância, apenas lembramos o quanto o debate da relação campo-cidade/ rural-urbano permeia
} 
estaria relacionada com o aprofundamento da "divisão territorial do trabalho" (MOREIRA, 2012, p. 18) e suas correlatas formas de percepção e compreensão desse processo em diferentes planos. Curiosamente, se as formas de acumulação e de reprodução da riqueza se davam predominantemente no campo, como, por exemplo, com a produção de café, de cana, da extração da borracha, entre outros, é a cidade, porém, que simbolizará avanço, o progresso, o mundo cultivado e o bom gosto.

Expressão mais sistemática e abrangente dessa visão de mundo dicotomizada, e aproximando-se mais da questão literária, será manifesta no ensaio de Afonso Arinos, "Nacionalização da arte" (1894). O artigo do escritor mineiro é uma resposta a um jornalista/jurado que havia criticado o seu conto rural "A esteireira" (incluído depois ao livro, Pelo sertão, em 1898) em razão da sua violência. Afonso Arinos (2014, p. 321) reconhece que não há como "tratar o animal humano destas Gerais, bravio, crescido às grosseiras carícias dos ventos da Chapada, de músculos retesados em pugnas primitivas contra as feras, as matas e os rios caudais, pelo molde do Rio de Janeiro e de São Paulo, daqui do meio da indústria, das estradas de ferro". Ou seja, "o animal humano" das Gerais pede um outro molde literário, necessariamente, para sua representação, diferente do indivíduo urbano.

Seria a de

E qual seria a especificidade desse outro modo de representação?

transmitir a outrem um pouco das impressões colhidas na natureza alpestre, selvática e brutesca do grande planalto central do Brasil, um pouco do perfume da charneca, das paixões bravias desses homens que moram a duzentas léguas do litoral, sem lei nem grei, habitantes de tugúrios à beira dos rios ou de palhoças batidas de vendavais, penduradas em vales estreitos, sem outros tetos que não a

as teorias do desenvolvimento sobre o capitalismo no Brasil.) Longe de pretender que os estudos literários tivessem o mesmo tipo de inclinação, anotamos apenas que a relação entre campo e cidade, espaço rural e espaço urbano, nos estudos literários brasileiros, foi bastante menosprezada ou mesmo desconsiderada, particularmente no que diz respeito aos potenciais momentos de transição nos quais talvez pudéssemos identificar e analisar com mais clareza as transformações em certas formas literárias e o que estaria implicado nessas transformações, do ponto de vista literário e social - articulações essas que são o foco de interesse da nossa pesquisa em geral e deste artigo em particular. 
folha do indaiá ou do baguaçu, sem outras paredes que não vigas de paus-a-pique, unidos, dormindo em jiraus sobre couros de jaguares ou de lobos (ARINOS, 2014, p. 322).

Já havíamos apontado em outro momento que a visão presente no artigo se compõe de "um entrecruzamento ou de uma mistura curiosa de telurismo local com certa condição social-limite das coisas" (GIL, 2014, p. 50). Afonso Arinos parece sugerir "uma espécie de mística do homem rude/pobre e do seu meio" (ARINOS, 2014, p. 322), que poetizaria o sertanejo e o "seu" mundo. A sua condição social precária limite seria subsumida pela poética do telurismo, a qual, por sua vez, "não deixa de pressupor a precariedade, ou se quisermos, a 'proximidade à natureza' (o caráter selvagem e bruto, o convívio longe do litoral, ausências de normas, a sobrevivência material com o que a natureza fornece aos homens etc.)" (GIL, 2014, p. 50).

Ainda do artigo de Afonso Arinos (2014) vale destacar um outro ponto que sublinha a ênfase que a distinção entre campo e cidade passa a ter para os escritores, a partir desse período, conforme se está procurando demonstrar. Arinos (2014, p. 322) anota que o sertanejo do seu conto e o crítico da Gazeta, a despeito da distância que os separa, "estão neste ponto exatamente iguais - desconhecem-se reciprocamente". Em outras palavras, nos diz que o mundo civilizado, letrado e urbano ignora os grotões do país, como o homem dos grotões, muito mais, desconhece o mundo civilizado, letrado e urbano.

Esta observação de Arinos (2014) sugere antecipar, em alguns anos, a percepção mais radical que se configurou, naquela quadra, a respeito da compreensão do caráter disruptivo entre os homens do campo, do interior, do mundo rural e da cidade, que foi formulada na obra $O s$ sertões (1902), de Euclides da Cunha, ao narrar a guerra de Canudos e apresentar a terra e o homem, ou os homens, envolvidos na batalha. Um dos traços do conflito que marcou a visão de Euclides da Cunha, como se sabe, foi o da natureza social partida e distinta do país. Sob este aspecto, Euclides observa que, "mal unidos àqueles extraordinários patrícios pelo solo em parte desconhecido, deles de todo nos separa uma coordenada histórica - o tempo" (CUNHA, 2001, p. 66). Desconhecimento geográfico e distanciamento temporal histórico (e também étnico, não estaríamos errado em acrescentar) demarcam, para o escritor, os fatores da separação "civilizatória" entre litoral e sertão. Nisso está implicada a perspectiva de que o homem do interior, do campo, no caso o sertanejo, é uma espécie de 
“outro". O sertanejo, como elemento "retrógrado" e "retardatário", como "força desvairada, perdida no sertão" (CUNHA, 2001, p. 338), seria o resultado de uma clivagem histórico-temporal de três séculos (CUNHA, 2001, p. 205). O sertão e o sertanejo, combinados, definem o que seria "aquele afloramento originalíssimo do passado, patenteando todas as falhas da nossa evolução" (CUNHA, 2001, p. 503). Tal afloramento teria sido abandonado e esquecido pelo processo civilizatório. Para os que chegassem por aquelas paragens sertanejas é como se estivessem "fora da pátria", "nesta transição violenta", nesta "discordância absoluta e radical entre as cidades da costa e as malocas do interior" (CUNHA, 2001, p. 677):

Viam-se [os soldados e o exército em geral] em terra estranha. Outros hábitos. Outros quadros. Outra gente. Outra língua mesmo, articulada em gíria original e pinturesca. Invadia-os o sentimento exato de seguirem para uma guerra externa. Sentiam-se fora do Brasil. A separação social completa dilatava a distância geográfica; criava a sensação nostálgica de longo afastamento da pátria (CUNHA, 2001, p. 677).

A invasão de "território estrangeiro" (CUNHA, 2001, p. 678), em confronto com essa “outra gente", falando uma "outra língua”, se dá sob o signo da violência. Os sertões são, no período em debate, a expressão social da consciência traumática mais radical de um país fraturado, manifesto, no seu ápice, nas formas diferentes e variadas de brutalidade entre sujeitos sociais que se desconhecem reciprocamente.

Posto isso, talvez seja importante, nesta altura, organizar algumas pontas dos fios da argumentação apresentada até aqui para dar o passo seguinte na nossa formulação. Nosso ponto de vista parte da ideia de que (a) ao longo do século XIX foi se desenvolvendo, gradativamente, uma consciência maior da distinção entre campo e cidade, entre vida rural e urbana, entre homem do campo e da cidade. Do romantismo às primeiras duas décadas do século $\mathrm{XX}$ se tem um movimento que se caracteriza, em esquema, do seguinte modo: no primeiro momento, tem-se uma diferenciação indistinta no qual o mundo rural é visto, compreendido e representado como um outro espaço, mas ele é ainda parte naturalmente constitutiva de algo maior e dominante que é a perspectiva da cidade e seus sistemas de valores; no segundo, estabelece- 
se a distinção dicotômica entre campo e cidade, em que o reconhecimento da diferença dos espaços sociais implica a percepção da particularidade aparentemente autônoma, às vezes contraditória, quando não tensa e conflitiva, de ambos. Este processo de acirramento das diferenças está relacionado (b) ao aprofundamento da divisão territorial do trabalho e sua correlata percepção (variada) do processo por nossos escritores. (c) Esta diferenciação, por sua vez, começa a tomar expressão plena e acaba por se configurar uma visão do país e uma maneira de compreendê-lo, tanto no âmbito da consciência literária que observa a necessidade de novas formas de ficcionalização do homem rural, dos grotões, em face do sujeito urbano - como se viu no ensaio de Afonso Arinos (2014) -, quanto na consciência histórica e social dos escritores, que em contextos mais radicalizados e extremos parecem constituir uma espécie de fissura traumática civilizatória quase que insolúvel do ponto de vista do seu equacionamento na dinâmica do processo histórico e social, como no caso de Os sertões, de Euclides da Cunha.

O segundo passo da nossa formulação, que se quer menos que uma hipótese e mais que uma intuição, pretende sugerir que é nessa quadra literária e histórica, os dois primeiros decênios do século XX, que o conto rural começa a ganhar corpo e alma como gênero literário, ou subgênero literário. Dito de outro modo, numa divisão social do trabalho intelectual (e literário) que tendeu, também ela, a se tornar um tanto mais complexa e diferenciada, ${ }^{7}$ incluído o âmbito dos gêneros e dos procedimentos técnicos

\footnotetext{
${ }^{7}$ Antonio Candido, nesse sentido, observa, no ensaio "Literatura e cultura de 1900 a 1945", que o espírito da burguesia e da intelectualidade ao longo do processo formativo, os séculos XVIII e XIX, "se desenvolveu sob os influxos dominantemente literários" (CANDIDO, 1976, p. 133), fazendo com que a sua forma de interpretar o mundo fosse estilizada em termos de literatura, dada a impossibilidade não somente de institucionalização de outra forma de conhecimento e discurso (o científico, o filosófico etc.), mas também em razão da urgência da tarefa social da construção da ordenação política e jurídica do país, sobretudo após a Independência, em 1822. No percurso de longa duração do caráter onívoro e onipresente da literatura, Os sertões seriam um marco no pensamento brasileiro - para além dos motivos indicados por nós - porque assinalam, segundo o ensaísta, um fim e um começo em relação a essa atitude e a essa tradição: "o fim do imperialismo literário, o começo da análise científica aplicada aos aspectos mais importantes da sociedade brasileira (no caso, as contradições contidas nas diferenças de cultura entre as regiões litorâneas e o interior)" (CANDIDO, 1976, p. 133). O livro de Euclides da Cunha mostra, assim, no momento histórico e literário
} 
e formais literários, o conto, como forma peculiar de composição ficcional e narrativa, parece configurar o gênero em prosa capaz de servir como experimento mais adequado às especificidades literárias que se abriam com a percepção dicotômica entre mundo rural e mundo urbano. Sendo parte constituinte do processo literário e histórico na virada do século, ele sugere possuir certo conjunto de aspectos formais mais pertinentes ao modo de lidar com a matéria rural, naquele momento, do que outras formas literárias.

Mencionamos já que o mundo rural é matéria presente de modo sistemático na tradição romanesca ao longo de todo o nosso romantismo; esta tradição introduziu aspectos peculiares ao romance rural como, por exemplo, as formas variadas de violência, como uma das motivações centrais da intriga, e também o caráter ambíguo do narrador em face da matéria rural. Embora estes pontos sigam a configurar a relação entre ficção e a matéria rural, o que estará em questão a partir de agora será a tentativa de criar uma linguagem específica ao mundo rural. Tratase de uma percepção estruturalmente diferenciada da necessidade de representação e constituição desse mundo do ponto de vista literário, que tem na linguagem, no sentido amplo do termo, o eixo central de preocupação.

$\mathrm{Na}$ "Introdução" à antologia que organiza d'O conto regionalista: do romantismo ao pré-modernismo, Luiz Gonzaga Marchezan (2009, p. XVI) assinala três momentos de transformação ocorrida no interior da narrativa rural curta da passagem do "conto romântico regionalista", que iria mais ou menos de 1830 a 1870, ao período pós-romântico e pré-modernista, que teria como marco os anos de 1870 até os anos 20 do século XX. No "conto romântico regionalista",

temos $[\ldots]$ o espaço americano, sem medida, paradisíaco. Os contos precursores da literatura brasileira são discursos ocorrenciais do discurso-tipo clássico; não tem dimensionado um espaço típico para as histórias do campo, a não ser uma réplica do lugar ameno, o grego.

que se tem em foco, como já "estavam modificadas as condições de formação do nosso pensamento, com indícios de superação da tirania jurídico-retórica" (CANDIDO, 1976, p. 133). É no quadro dessa complexificação do trabalho intelectual e literário que pensamos situar a relevância que a narrativa curta passa a ter para a matéria rural no âmbito das formas literárias. 
Desse modo, as narrativas regionalistas ficam presas às descrições de estados, que contrastam, de forma eloquente, grandes valores humanos diante de grandes valores naturais, buscando, dessa maneira, fixar a atenção do ouvinte para a exuberância do lugar (MARCHEZAN, 2009, p. XV-XVI).

Já os escritores pós-românticos e pré-modernistas encenariam, “de forma crescente, uma diversidade de relações temático-figurativas: casos, situações vividas por vaqueiros, tropeiros - grupos e valores culturais que entram em cena diante de um cenário típico" (MARCHEZAN, 2009, p. XVI). O organizador da antologia ainda fixa diferenças entre os pósromânticos e os pré-modernistas, que ficam assim assinaladas:

[...] num primeiro momento, lemos no conto regionalista pós-romântico o predomínio do discurso descritivo, que sobrepõe a voz autoral, o que ela observa, às demais. [...] Com os contistas regionalistas pré-modernistas o narrador ganha percepção cognitiva e referencializa o espaço do sertão, o lugar discurso de onde se fala, local em que circula determinado discurso (MARCHEZAN, 2009, p. XVII-XVIII).

Em que pese Luiz Marchezan, na sua "Introdução", não tenha como objetivo estudar a particularidade da contística rural no quadro geral da prosa de ficção e tampouco considere as condições literárias e históricas que levam às mudanças formais internas ao gênero, dois fatores que para a nosso estudo são centrais à compreensão do dinamismo histórico-literário da relação entre o conto do início do século XX e a matéria rural; em que pese a falta de preocupação com estes pontos, dizíamos, há de se destacar todavia que o antologista apreende uma diferença constitutiva entre o conto pós-romântico e o "pré-modernista"8 que merece atenção. $\mathrm{O}$ conto pós-romântico, para o crítico, seria ainda

\footnotetext{
${ }^{8}$ Sabemos o quanto são problemáticas as noções que tendem a periodizar a literatura brasileira, particularmente a de "pré-modernismo", no que se traduz numa compreensão teleológica, centralista e hegemônica do modernismo brasileiro para a nossa crítica e história literárias. O próprio estudo da ficção rural, sob vários aspectos que não podem ser abordados no momento, demonstraria a centralidade apenas relativa do modernismo na literatura brasileira. $\mathrm{O}$ uso da categoria aqui se vincula ao ponto de vista do autor da antologia.
} 
dominado pela voz do autor-narrador, caracterizada por uma espécie de hipertrofia em relação às demais instâncias ficcionais. A formulação de Marchezan (2009) é um tanto genérica, mas não pareceria equivocado dizer que o seu ponto de vista aqui se entronca com a observação feita por nós páginas antes: assim como no romance rural do período, também no conto rural o domínio da "palavra culta" e o seu sistema ideológico correlato (urbano e letrado) seriam o que predomina. Entretanto, olhando as coisas mais de perto, não se pode desconsiderar que o processo evolutivo do conto rural, desde o período pós-romântico, aponta para diferenças expressivas comparativamente ao romance que ainda estão por merecer estudos. Para se dar apenas um exemplo que ao mesmo tempo atende aos objetivos deste artigo, é interessante ao menos anotar a variação da dicção literária presente na obra de um mesmo autor, como o Visconde de Taunay, quando recorre ao romance, como em Inocência (1872), e quando se utiliza da narrativa curta em "Juca, o tropeiro" (1874). No caso, é bastante significativa a configuração do narrador, específica em cada um dos casos, em face da matéria e do mundo rurais. Enquanto em "Juca, o tropeiro" se tem nitidamente o processo de mimetização da linguagem oral, que não somente tende a um "tom dialetal sertanejo", como também figura o narrador como um contador de um "causo" que se dirige a um público virtual de ouvintes, ${ }^{9}$ em Inocência inexiste a figura do narrador como contador de causo em linguagem "local", a qual por sua vez se limita à fala de um ou outro personagem. No conto, o narrador se quer como parte da paisagem humana e física relatada; no romance, ele se põe como sujeito distinto da matéria narrada.

${ }^{9}$ É interessante notar que Taunay parece ter consciência de muitos dos aspectos de linguagem que a criação de "Juca, o tropeiro" envolvia e que estão expostos na "Advertência" do conto, retirada da edição organizada por Luiz Gonzaga Marchezan, mas a qual transcrevemos devido à sua importância: "A autoria da presente narração pertence mais a um ex-sargento de voluntários de Minas, que nos disse haver conhecido de perto o personagem que nela figura, do que a nossa pena. / O que fizemos foi desbastar o correr da história de incidentes por demais longos, de inúmeros termos familiares, e sobretudo de locuções chulas e sertanejas que podiam por vezes parecer inconvenientes. Havendo contudo reconhecido a originalidade e força de colorido dessa linguagem, e desejando conservar ainda um quê da ingênua, mas pitoresca expressão do narrador, resultou uma coisa esquisita, nem como era quando contada pelo ex-sargento, nem como deveria ser, saída da mão de quem se atira a escrever para o público. / Batemos de arrependido nos peitos" (TAUNAY, 2014, p. 287). 
Este caso sinaliza e explica, ao menos em esquema, a passagem de uma configuração formal à outra, apenas indicada por Marchezan (2009), mas não analisada em suas motivações internas. A ideia de que a contística rural das duas primeiras décadas do século XX opera, em boa medida, com um narrador que "ganha percepção cognitiva e referencializa o espaço do sertão, o lugar do discurso de onde se fala, local em que circula determinado discurso" sugere somente poder ser compreendida crítica e profundamente, em suas várias dimensões, quando se busca examinar a peculiaridade formal do gênero num dado contexto, a sua relação com a matéria particular a ser ficcionalizada e as modificações, históricas e formais, implicadas nestas transformações. Assim, quando dissemos que o exemplo das narrativas do Visconde de Taunay serve à explicação da passagem de uma configuração literária à outra queremos propor duas coisas. Primeiro, que o romance, como forma ficcional e narrativa, parece ter um tempo necessário de longa duração para dar conta da matéria rural a partir da criação de dispositivos formais e procedimentos literários técnicos capazes de figurar literariamente a especificidade dessa matéria; aspectos e relação de maturação formal que somente uma investigação de longo alcance da forma romance, em termos empíricos e analíticos, poderia decifrar e entender no seu conjunto. Segundo, o conto, ao contrário, e diferentemente do que apresenta a formulação de Marchezan (2009) na relação que estabelece entre a narrativa pós-romântica e "pré-modernista", trouxe em si e consigo a possibilidade de estabelecer formalização literária mais adequada e pertinente em face do referente histórico dado pelo mundo rural, desde um texto como "Juca, o tropeiro", como se anotou. Projetando estas observações nas formas literárias concretas, e sem imaginar que se trate de uma solução de continuidade mecânica de causa-efeito redutora e teologicamente orientada, não é difícil de notar, apenas para ilustrar, que o caminho entre "Juca, o tropeiro" e as narrativas de Contos gauchescos (1912), de Simões Lopes Neto, perfaz uma trajetória histórica e literária de maturação mais rápida e talvez com articulações mais "visíveis" no interior do subgênero (mas sempre ainda a serem demonstradas) do que entre Inocência (1872) e Grande sertão: veredas (1956), de Guimarães Rosa.

O fato de esta maturação literária se efetivar num trânsito histórico-literário de mais curta duração não pode ser demonstrado como "propriedades intrínsecas à contística" somente. Qualquer esforço crítico 
que plaine em abstrato e de modo genérico apenas em teorias inerentes a gêneros ou subgêneros literários, qualquer que seja ela, corre o risco de perder de vista não somente as mutações formais da narrativa curta como também as articulações históricas e culturais que possam ter agido no interior destas transformações em nosso contexto. Em uma palavra, esvazia-se a historicidade da forma em exame.

Assim podemos levar adiante a formulação pretendida e dizer que no nosso sistema cultural e literário, o conto, enquanto forma literária de origem letrada e culta, sugere estar mais próximo da linguagem e das formas narrativas orais populares, do "causo" às lendas, passando pelo folclore, mitos etc. Digamos que as matrizes populares do mundo oral e iletrado, presentes também nas cidades, mas dominantes no mundo rural, encontraram no conto uma possibilidade estrutural mais proximamente análoga quando vertida à letra impressa. Esta contiguidade estrutural parece ser chave à compreensão da articulação, do adensamento e da acumulação literárias possíveis entre as matrizes orais populares e o conto rural de origem letrada. Deste modo, a distinção dicotômica da divisão territorial do trabalho, que passa a ver de modo intensificado os contrastes e as contradições entre campo e cidade, homem da cidade e do campo, entre o estilo de vida rural e urbano etc., e que se torna, portanto, parte significativa da experiência mental, histórica e cultural dos nossos escritores, talvez adquira no conto rural, nos dois primeiros decênios do século XX, o precipitado formal capaz de dar corpo, forma e expressão a esta tensão que se descortina na experiência brasileira. Ao mesmo tempo, num movimento dúplice, as incorporações da matéria rural no âmbito da forma conto somente são possíveis em razão da agudização que se esboçou no interior desta distinção dicotômica.

De outra parte, é importante enfatizar que é também a partir de período próximo, todavia um pouco posterior em relação ao da contística rural que está em foco aqui, que a ensaística brasileira passa a redimensionar os "domínios rurais", a "herança rural", de modo sistemático e conceitual, no pensamento histórico e social brasileiro. Em outras palavras, quer-se chamar atenção para o fato de a compreensão da distinção dicotômica da divisão territorial do trabalho ter gerado um movimento convergente, embora com um pequeno lapso de tempo histórico, entre a contístisca rural - que pretende incorporar a matéria rural como estruturalmente constitutiva do discurso literário, no âmbito da linguagem, da instância narrativa e espacial, gerando 
certa forma cognitiva particular em face dessa nova configuração - e a ensaística social brasileira - que parece ter condições e necessidade de redimensionar a experiência rural desde o período colonial. Assim, entre as narrativas de Coelho Neto, Simões Lopes Neto, Hugo de Carvalho Ramos, Monteiro Lobato e Valdomiro Silveira e o pensamento de Oliveira Vianna, em Evolução do povo brasileiro (1922), de Gilberto Freyre, em Casa-grande e senzala (1933), de Sérgio Buarque de Holanda, em Raízes do Brasil (1936), de Caio Prado Junior, em Evolução política do Brasil (1933) e Formação do Brasil contemporâneo (1942), é possível haver um veio subterrâneo comum entre a nossa experiência literária e o nosso pensamento social, que está por merecer investigação ainda. ${ }^{10}$

Num último passo destas notas, gostaríamos de sinalizar, ao menos de passagem, como se traduziu em alguns aspectos do âmbito literário e da consciência social dos nossos escritores esta intensificação da presença do rural em nossa experiência social, cultural e literária. Trata-se, bem entendido, de uma presença sempre variada, diversa e contraditória, de um ficcionista para outro ou mesmo no interior da obra de um mesmo escritor.

Talvez a obra de Monteiro Lobato seja uma espécie de mina preciosa para tentar captar algumas das questões que estavam em jogo ali entre 1900 e 1920, que é o período que nos interessa, mas também o é para depois dele. A abrangência e a importância da atuação de Lobato em diferentes frentes profissionais, bem como a sua produção em gêneros os mais diversos, explicam, ao menos em parte, sua destacada presença naquele momento. Interessa-nos, agora, tão somente pontuar alguns elementos que estão no livro de contos Urupês, publicado em 1918.

Esta obra, como se sabe, não é somente um livro de narrativas ficcionais. Os dois últimos textos, "Velha praga" (1914) e o que dá título ao livro, expõem a visão lobatiana sobre o caboclo e o "caboclismo" na vida social e cultural do sertão paulista, em particular, e do mundo rural como um todo. "Velha praga", "parasita", "sarcoptes", "urupê”, “jeca-

\footnotetext{
${ }^{10}$ Uma pesquisa detalhada e inovadora do problema deveria se ater, entre outras coisas, na matização das diferenças da presença do rural como explicação da formação social brasileira nesses "intérpretes do Brasil" e suas possíveis relações com a visão literária que a contística configura do mundo rural nos dois primeiros decênios do século XX. Claro que não podemos desconsiderar, no caso dos anos 1930, a força que o romance rural volta a ter.
} 
tatu", entre outras, todas são expressões com as quais Monteiro Lobato traduz sua visão derrisória do caboclo do campo, que para ele, em "Velha praga", se caracteriza por ser

\begin{abstract}
espécie de homem baldio, seminômade, inadaptável à civilização, mas que vive à beira dela na penumbra das zonas fronteiriças. À medida que o progresso vem chegando com a via férrea, o italiano, o arado, a valorização da propriedade, vai ele refugindo em silêncio, como seu cachorro, o seu pilão, a pica-pau e o isqueiro, de modo a sempre conservar-se fronteiriço, mudo e sorna. Encoscorado numa rotina de pedra, recua para não adaptarse (LOBATO, 2014, p. 165).
\end{abstract}

A esta "quantidade negativa" (LOBATO, 2014, p. 168) que define o caboclo se associaria, ainda, o seu poder destrutivo geral em relação às formas de produção e exploração do solo e da natureza, mal-estar aparentemente maior de Monteiro Lobato nesse texto, diga-se.

Se em "Velha praga" o argumento se detém na figura e na vida semisselvagem, incivilizável e "incivilizatória" do caboclo e também na sua ação supostamente devastadora em razão do modo como atua na natureza, em "Urupês" (1914), por sua vez, sem que estes aspectos percam a sua centralidade, a eles se vinculam duas outras facetas que queremos particularmente destacar. A primeira remete à ideia, mais propriamente literária, de que o "caboclismo" veio a substituir o indianismo. Com a mesma altivez e virilidade heroica dos Peris e dos Ubirajaras, emergiria a figura do Jeca-Tatu que, de D. Pedro I a Floriano, alheio a tudo, como sempre "continua de cócoras, a modorrar" (LOBATO, 2014, p. 171). Embora "bonito no romance", ele é "feio na realidade" (LOBATO, 2014, p. 172). A segunda, comentada no mesmo tom contundentemente sarcástico, se refere ao fato de que, ao contrário da "arte rústica do campônio europeu [que] é opulenta a ponto de constituir preciosa fonte de sugestões para o artista de escol" (LOBATO, 2014, p. 179), "não denuncia o nosso caboclo o mais remoto traço de um sentimento [artístico ou estético] nascido com os trogloditas" (LOBATO, 2014, p. 179) em face da arte. Completa ainda Lobato (2014, p. 179-180) ao final:

O caboclo é soturno.

Não canta senão rezas lúgubres.

Não dança senão o cateretê aladainhado. 
Não esculpe o cabo da faca, como o cabila.

Não compõe a sua canção, como o felá do Egito.

$[\ldots]$

Só ele não fala, não canta, não ri, não ama.

Só ele, no meio de tanta vida, não vive...

Observe-se que a apresentação rebaixada do caboclo, misturada muitas vezes ao virulento tom de escárnio, não encontra sustentação em premissas científico-raciais, típicas do final do século XIX, mas com forte vigência ainda na entrada do XX. Embora a noção de "caboclo", advinda originariamente da fusão do índio com o branco, refira-se a formações étnicas, parece-nos que ela é utilizada por Monteiro Lobato, nos textos em foco, em sentido mais amplo e genérico para definir um tipo de habitante rural, o caipira, o matuto, o roceiro. O que parece ser recorrente na formulação sobre o "caboclismo" de Lobato é a permanência negativa e pessimista da (in)constituição da nacionalidade, ou ao menos o seu caráter problemático, encarnada por um dos seus elementos, que é a figura social do caboclo. Interessa-nos, neste ponto, sublinhar como o sentimento e a posição derrogatórios de Monteiro Lobato em face do caboclo se mostram estreitamente ligados ao modo como o espaço rural emerge à consciência dos nossos escritores nesse momento. E tal posição e sentimento somente parece ser possível porque, como já se destacou, o espaço rural passou a ser uma noção específica no modo de ver e compreender o país a partir desse momento. Para o autor de Cidades mortas, como se percebe, o "caboclismo" é emblema e síntese do mundo rural, no que esse representa de atraso, de anticivilizatório, de fator que trava e encalacra o país, o campo em particular, jogando-o à margem do progresso. Se ele é a expressão do encoscoramento "numa rotina de pedra, [que] recua para não adaptar-se" diante da ferrovia, do italiano, do arado e da valorização da propriedade, é fato também que Lobato cristaliza a visão do caboclo como um miasma social de modo a desmarcá-lo de qualquer razão social e histórica, de qualquer fator explicativo mais consistentemente indicado. ${ }^{11} \mathrm{Nem}$ raça nem meio, nem história nem organização social aparecem como elemento explicativo. Como espécie de figura desde sempre presente na paisagem, é só nesse momento, porém, que ela consegue ganhar identidade própria, com

\footnotetext{
${ }^{11}$ Sabe-se que anos depois o autor vai relativizar esta sua compreensão do Jeca-Tatu, inicialmente presente no livro Urupês.
} 
corpo, alma e "estilo de vida", configurada no que de mais retrógrado pode se originar do mundo rural.

$\mathrm{Na}$ contramão desta posição, e no mesmo livro de Lobato, emerge uma outra perspectiva desses habitantes do campo, bem menos desabonadora e, digamos, mais compreensiva do que a dos textos anteriores. Veja, nesse sentido, como o narrador culto do conto "O matapau" (1915) se refere à história que lhe fora transmitida pelo homem do campo e que agora ele passa a narrar:

O camarada contou a história que para aqui translado com a possível fidelidade. O melhor dela evaporou-se, a frescura, o correntio, a ingenuidade de um caso narrado por quem nunca aprendeu a colocação dos pronomes e por isso mesmo narra melhor que quantos por aí sorvem literaturas inteiras, e gramáticas, na ânsia de adquirir estilo. Grandes folhetinistas andam por este mundo de Deus perdidos na gente do campo, ingramaticalíssima, porém pitoresca no dizer como ninguém (LOBATO, 2014, p. 118).

Será que esta visão mais conscienciosa e inclusiva do homem de letras para com a arte de narrar da "gente do campo" ainda diria respeito à máxima lobatiana de que na literatura o caboclo pode ser "bonito" e na realidade não? Parece-me que não se trata só disso, mesmo porque o caipira protagonista do conto, Elesbão, é o antijeca-tatu, como nos conta o narrador: "Elesbão, rijo no trabalho, prosperou. Aos três anos de labuta era já sitiante de monjolo, escaroçador e cevadeira, com dois agregados no eito" (LOBATO, 2014, p. 119).

A perspectiva de Monteiro Lobato traduz e sintetiza em si ao menos parte das questões com que o conto rural de modo muito variado, mas sempre contraditório, se defronta e busca superar naquele momento. Se pudermos delinear os seus índices gerais a partir do que foi sugerido pela rápida leitura dos textos de Lobato, poderíamos anotar o seguinte: 1) os textos de Lobato sinalizam com clareza e por inteiro os campos sociais (de classe), culturais e literários diferenciados entre o homem de letras, indivíduo da cultura escrita e da cidade, e o homem do campo, da cultura oral e ligado ao trabalho rural. Esta distinção e separação, por estranha que possa parecer e como se procurou argumentar ao longo deste trabalho, não estava dada e constituída plenamente do ponto de vista social e literário em nosso contexto. 2) Como se pôde depreender, extremos podem emergir da percepção do "outro"e do seu mundo 
social, que vai desde a tentativa de sua caracterização e, passo seguinte, à sua desqualificação e mesmo nulificação social e cultural, até o seu reconhecimento e reposição social e cultural (de grandes proseadores que são, "grandes folhetinistas [que] andam por este mundo de Deus perdidos na gente do campo", a pertinazes trabalhadores). 3) A contística lobatiana, ao fazer a distinção literária entre o eu do escritor culto e o da figura rural, não deixa de se esbater nos seus próprios limites, não somente quando afirma com plena consciência que o modo de narrar o mundo rural lhe escapa ("O melhor dela evaporou-se, a frescura, o correntio, a ingenuidade de um caso narrado por quem nunca aprendeu a colocação dos pronomes"), mas sobretudo quando de fato a letra escrita ainda não consegue verter-se em "letra escrita oralizada". 4) A consciência literária inclusiva da matéria rural que Monteiro Lobato expressa, mas à qual não dá forma, será, sim, capaz de ser revertida em outros autores, como, por exemplo, nos contos de Simões Lopes Neto e, até certo ponto, nos de Valdomiro Silveira, ao criar e produzir recursos técnicos e formais que vocalizem, em algum nível, a linguagem do outro rural, em sentido amplo. Este último ponto, no entanto, deve ser assunto de outro artigo.

\section{Referências}

ARINOS Afonso. Nacionalização da arte. In: GIL, Fernando C. Ensaios sobre a formação do romance brasileiro: uma antologia (1836-1901). Curitiba: UFPR, 2014. p. 321-328.

CANDIDO, Antonio. Literatura e cultura de 1900 a 1945. In: Literatura e sociedade. 5. ed. São Paulo: Nacional, 1976. p. 109-138.

COSTA, Emília Viotti da. A urbanização no Brasil no século XIX. In: . Da monarquia à república: momentos decisivos. 7. ed. São Paulo: UNESP, 1999. p. 233-270.

CUNHA, Euclides da. Os sertões: campanha de Canudos. 2. ed. São Paulo: Ateliê, Imprensa Oficial do Estado, Arquivo do Estado, 2001.

GIL, Fernando C. Ensaios sobre a formação do romance brasileiro: uma antologia (1836-1901). Curitiba: UFPR, 2014.

GUIMARÃES, Bernardo. O índio Afonso. In: - Quatro romances. São Paulo: Sociedade Brasileira de Difusão do Livro, [s.d.]. p. 363-364. 
LOBATO, Monteiro. Contos completos. São Paulo: Biblioteca Azul, 2014.

MARCHEZAN, Luiz Gonzaga. Introdução. In: (Org.). O conto regionalista: do romantismo ao pré-modernismo. São Paulo: WMF Martins Fontes, 2009. p. IX-XLIII.

MOREIRA, Ruy. As fases e vetores da formação espacial brasileira: hegemonias e conflitos. In: . Aformação espacial brasileira: uma contribuição crítica à geografia do Brasil. Rio de Janeiro: Consequência, 2012. p. 9-29.

NABUCO, Joaquim. O abolicionismo. Rio de Janeiro: Nova Fronteira; São Paulo: Publifolha, 2000.

ROMERO, Sílvio. O nacionalismo literário. In: GIL, Fernando C. Ensaios sobre a formação do romance brasileiro: uma antologia (1836-1901). Curitiba: UFPR, 2014. p. 435-442.

TAUNAY, Visconde de. Advertência de Juca, o tropeiro. In: GIL, Fernando C. Ensaios sobre a formação do romance brasileiro: uma antologia (1836-1901). Curitiba: UFPR, 2014. p. 287.

VERÍSSIMO, José. O que falta à nossa literatura. In: GIL, Fernando C. Ensaios sobre a formação do romance brasileiro: uma antologia (18361901). Curitiba: UFPR, 2014. p. 497-501. 